\title{
Inhibition of the early asthmatic response to inhaled allergen by the 5-lipoxygenase activating protein inhibitor GSK2 1909 I5: a dose-response study
}

\author{
This article was published in the following Dove Press journal: \\ International Journal of General Medicine \\ 6 December 2013 \\ Number of times this article has been viewed
}

\section{Dave Singh' \\ Malcolm Boyce ${ }^{2}$ \\ Virginia Norris ${ }^{3}$ \\ Sandra E Kent ${ }^{3}$ \\ Jane $\mathrm{H}^{\text {Bentley }}{ }^{3}$}

'University of Manchester, Medicines Evaluation Unit, University Hospital of South Manchester, Manchester, UK; ${ }^{2} \mathrm{Hammersmith}$ Medicines Research, London, UK; ${ }^{3} \mathrm{GlaxoSmithKline,}$ Middlesex, UK
Correspondence: Virginia Norris GlaxoSmithKline, Brentford, Middlesex, TW8 9GS, UK

Tel +442080476634

Fax +442080470666

Email virginia.h.norris@gsk.com
Background: GSK2190915, a 5-lipoxygenase activating protein inhibitor, inhibits the production of cysteinyl leukotrienes and leukotriene B4 and 5-oxo-6,8,11,14-eicosatetraenoic acid. We have previously reported that GSK2190915 $100 \mathrm{mg}$ daily inhibits early and late asthmatic responses to inhaled allergen; the effects of lower doses have not been reported. This study assessed the dose-response effects of GSK2190915 $10 \mathrm{mg}$ and $50 \mathrm{mg}$ on the early asthmatic response (EAR) to inhaled allergen.

Methods: Nineteen subjects with mild asthma and an EAR were enrolled in a randomized, double-blind, three-way crossover study of GSK2190915 $10 \mathrm{mg}, 50 \mathrm{mg}$, and placebo orally once-daily for 3 days. Allergen challenge was performed 2 hours after the third dose.

Results: Compared with placebo, GSK2190915 $10 \mathrm{mg}$ and $50 \mathrm{mg}$ caused significant, dosedependent attenuation of the minimum forced expiratory volume at 1 second $\left(\mathrm{FEV}_{1}\right)$ absolute change from baseline; mean treatment differences were $0.21 \mathrm{~L}$ (95\% confidence interval [CI] $0.04 \mathrm{~L}, 0.38 \mathrm{~L})$ and $0.41 \mathrm{~L}(95 \%$ CI $0.24 \mathrm{~L}, 0.58 \mathrm{~L})$, respectively. GSK2190915 $50 \mathrm{mg}$ was more effective than $10 \mathrm{mg}$; mean difference between treatments was $0.20 \mathrm{~L}$, (95\% CI $0.03 \mathrm{~L}$, $0.36 \mathrm{~L}$ ). Compared with placebo, GSK2190915 $50 \mathrm{mg}$, but not $10 \mathrm{mg}$, significantly inhibited the weighted mean $\mathrm{FEV}_{1}$ absolute change from baseline.

Conclusion: GSK2190915 $50 \mathrm{mg}$ attenuated the EAR similarly to GSK2190915 $100 \mathrm{mg}$ in our previous study, suggesting $50 \mathrm{mg}$ is at the top of the dose-response curve. GSK2190915 $10 \mathrm{mg}$ is a suboptimal dose. The EAR can be used to assess the therapeutic dose of a new treatment for asthma.

Keywords: GSK2190915, FLAP inhibitor, early asthmatic response

\section{Introduction}

Arachidonic acid (AA) within the cell membrane is metabolized by the enzyme 5-lipoxygenase (5-LO) to produce leukotrienes. ${ }^{1,2}$ The 5-LO activating protein (FLAP) binds to 5-LO in this process, enabling transfer of AA to 5-LO. AA metabolism produces leukotriene A4 (LTA4), which is subsequently converted to either LTB4 or the cysteinyl leukotrienes (cysLTs) LTC4, LTD4, and LTE4. CysLTs bind to cysLT1 and cysLT2 receptors, causing bronchoconstriction and eosinophilic inflammation, while LTB4 promotes the chemotaxis and activation of immune cells including neutrophils and lymphocytes through BLT1 and BLT2 receptors. AA metabolism by 5-LO also produces 5-hydroxyeicosatetraenoic acid (5-HETE), which is further metabolized to 
5-oxo-6,8,11,14-eicosatetraenoic acid (5-oxo-ETE); this activates neutrophils and eosinophils. ${ }^{3}$

CysLTs levels are elevated in the lungs of patients with asthma. ${ }^{4,5}$ CysLT receptor antagonists are used for the treatment of asthma, ${ }^{1}$ but do not inhibit LTB4 or 5-HETE activity. The 5-LO inhibitor zileuton is approved for the treatment of asthma, but the doses used in clinical practice only partially inhibit leukotriene production, and the therapeutic index is limited by side effects. ${ }^{1}$ There is no available drug that completely inhibits the actions of all of the mediators produced by the 5-LO pathway.

GSK2190915 is a novel potent FLAP inhibitor currently in development for the treatment of asthma (the FLAP pathway is detailed in Figure 1). ${ }^{6}$ It inhibits pulmonary cysLTs and $\mathrm{LTB}_{4}$ production in animal models, ${ }^{8}$ and inhibits $\mathrm{LTB}_{4}$ production by whole blood stimulated ex vivo and urine $\mathrm{LTE}_{4}$ excretion in healthy subjects. ${ }^{9}$

The inhaled allergen challenge model is widely used to characterize potential new treatments for asthma; inhibition of the early asthmatic response (EAR) demonstrates the ability to prevent acute allergic bronchoconstriction, whereas inhibition of the late asthmatic response (LAR) suggests effective

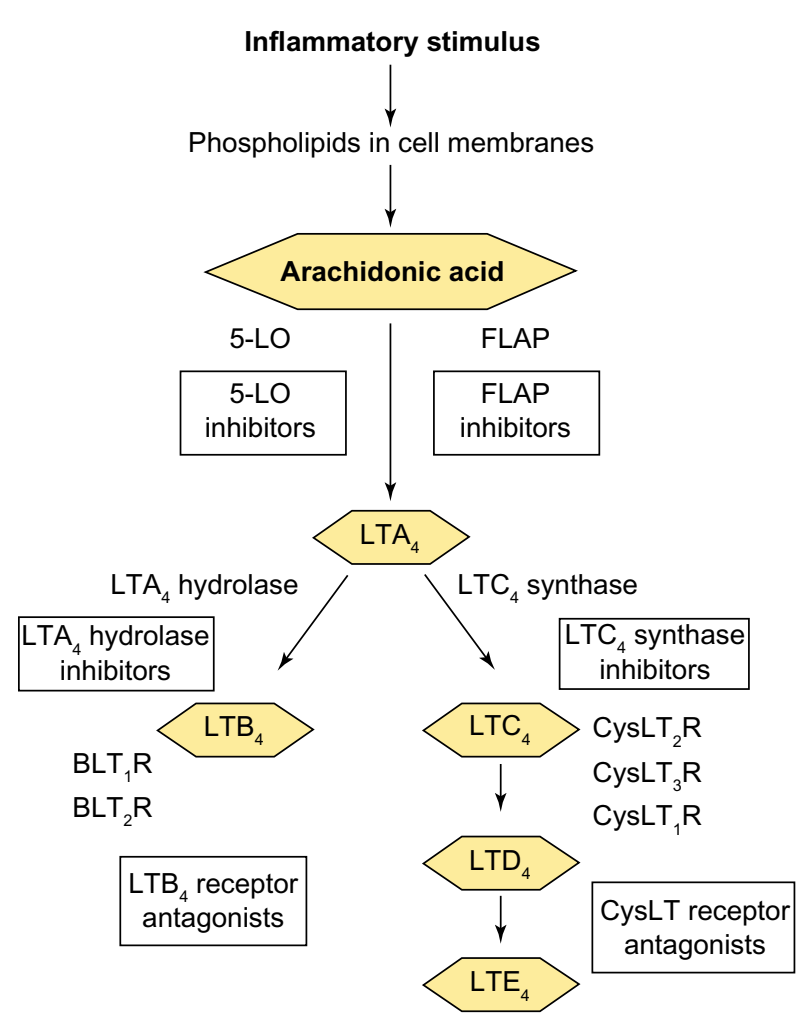

Figure I The 5-lipoxygenase activating protein (FLAP) pathway.

Notes: Reprinted from Trends Pharmacol Sci, 2007;29, Evans JF, Ferguson AD, Mosley RT, Hutchinson JH, What's all the FLAP about?: 5-lipoxygenase-activating protein inhibitors for inflammatory diseases, 72-78, Copyright (C) 2008, with permission from Elsevier. Also with permission from Panmira Pharmaceuticals.

Abbreviations: BLT, G-protein-coupled receptor for LT; Cys, cysteinyl; FLAP, 5-lipoxygenase activating protein; LO, lipoxygenase; LT, leukotriene. anti-inflammatory properties. ${ }^{710-15}$ We have recently shown that GSK2190915 $100 \mathrm{mg}$ daily inhibits both the EAR and LAR in subjects with mild asthma. ${ }^{7}$ Other FLAP inhibitors also attenuate both the EAR and LAR. ${ }^{12,13}$

The therapeutic dose of a new treatment for asthma is usually established by assessing its effect on pulmonary function tests and symptoms. Such studies require large numbers of subjects to discriminate between doses. ${ }^{16,17} \mathrm{We}$ have employed an alternative approach; we used the EAR to study the dose response effects of GSK2190915 in subjects with asthma. We have previously reported that GSK2190915 $100 \mathrm{mg}$ inhibits the EAR, ${ }^{7}$ but have not reported the effects of lower doses. We knew that GSK2190915 $50 \mathrm{mg}$ almost completely suppresses urinary LTE4 levels in healthy subjects, whereas $10 \mathrm{mg}$ causes incomplete suppression, ranging from $40 \%$ to $60 \%{ }^{9}$ Therefore, we chose to assess the effect of GSK2190915 $10 \mathrm{mg}$ and $50 \mathrm{mg}$ on the EAR in subjects with mild asthma, and to compare the results with those of the effect of GSK2190915 $100 \mathrm{mg}$ daily on the EAR from our previously reported study. ${ }^{7}$

\section{Materials and methods Subjects}

Nineteen nonsmoking subjects, aged 18 to 55 years, with mild asthma were recruited. Males and females of nonchildbearing potential were included; females of childbearing potential were not included as the appropriate reproductive toxicology studies had not been conducted at the time of the study. Other inclusion criteria were: body mass index within the range $18.5-35.0 \mathrm{~kg} / \mathrm{m}^{2}$; forced expiratory volume in 1 second $\left(\mathrm{FEV}_{1}\right)>70 \%$ predicted; current nonsmoker with a pack history of $\leq 10$ pack years; current asthma treatment with an inhaled short-acting beta agonist only; no use of inhaled corticosteroids for at least 1 month before screening; and asthma diagnosis confirmed by provocative methacholine or histamine concentration causing a $20 \%$ fall in $\mathrm{FEV}_{1}$ (provocative concentration $20\left[\mathrm{PC}_{20}\right]$ ) $<8 \mathrm{mg} / \mathrm{mL}$ ( or $<60 \mathrm{mg} / \mathrm{mL}$ for adenosine monophosphate challenge) within 6 months before screening or at the screening visit. Subjects were required to demonstrate an EAR at screening, defined as a fall in $\mathrm{FEV}_{1}$ of at least $20 \%$ from baseline during the 2 hours after allergen challenge. Exclusion criteria were: a respiratory tract infection and/or asthma exacerbation within 4 weeks of randomization; and the possibility of symptoms of hay fever at any time during the study. The study received ethical and regulatory approval before commencement (GSK Study Number LPA112356; clinicaltrials.gov: NCT00812773). Written informed consent was obtained from each subject, 
and the study was conducted in accordance with the International Conference on Harmonization Good Clinical Practice Guideline and Declaration of Helsinki.

\section{Study design}

The design was double-blind, three-way crossover, in three centers in the United Kingdom. Subjects were screened at least 14 days before the first treatment period. Eligible subjects received GSK2190915 $10 \mathrm{mg}$ and $50 \mathrm{mg}$ and matching placebo solutions by mouth with $100 \mathrm{~mL}$ water, once-daily for 3 days, in randomized order. Subjects fasted for at least 8 hours before dosing. Allergen challenge was performed at 2 hours after the third dose in each treatment period (Day 3). Treatment periods were separated by a minimum 14-day washout, to allow time for recovery from any allergeninduced hyperresponsiveness, which can persist for 2 weeks in subjects who have a LAR in addition to an EAR. The 14-day washout also exceeds five half-lives of GSK2190915 $\left(\mathrm{t}_{1 / 2} \sim 20\right.$ hours). There was a follow-up visit 5-21 days after the last dose of treatment.

\section{Allergen challenge}

Skin prick tests were performed on the volar aspect of the forearm using solutions of grass mix, house dust mite, and cat hair (ALK Abelló, Hørsholm, Denmark). A wheal of at least $3 \mathrm{~mm}$ diameter compared with the negative control solution (sodium chloride $0.9 \%$ ) was deemed positive. Generally, the allergen that produced the largest positive response was used for the allergen challenge test at screening, using incremental doses as described previously. ${ }^{7}$ Allergen challenge at screening was stopped when a $20 \%$ decrease in $\mathrm{FEV}_{1}$ was observed, indicating a positive EAR. The cumulative inhaled allergen dose that had produced an EAR at screening was subsequently administered as a single bolus dose on Day 3 of each treatment period. $\mathrm{FEV}_{1}$ was recorded every 5 minutes until 20 minutes, then at $30,45,60,90$, and 180 minutes after bolus allergen challenge. Subjects were monitored for safety for at least 4 hours after allergen challenge.

\section{Methacholine challenge}

Subjects with no documented result for methacholine, histamine, or adenosine monophosphate challenge within 6 months of screening completed a methacholine challenge at the screening visit to confirm study eligibility. $\mathrm{FEV}_{1}$ was recorded before and after the inhalation of five breaths of nebulized phenol-saline control to ensure that the control did not cause a fall in $\mathrm{FEV}_{1}>10 \%$ from the pre-saline measurement. The post-phenol saline $\mathrm{FEV}_{1}$ was the baseline value. Subjects then proceeded to inhale methacholine (Provocholine ${ }^{\circledR}$; Methapharm Europe, Geneva, Switzerland), starting at a concentration of $0.0625 \mathrm{mg} / \mathrm{mL}$, and increasing two-fold until the $\mathrm{PC}_{20}$ was reached. The concentration of methacholine did not exceed $8 \mathrm{mg} / \mathrm{mL}$. Subjects were monitored until lung function returned to within $10 \%$ of resting $\mathrm{FEV}_{1}$.

\section{Pharmacokinetics}

A $3 \mathrm{~mL}$ blood sample was taken on Day 3 at 2 hours after dosing, and plasma was separated by centrifugation $\left(4^{\circ} \mathrm{C}\right.$, $1,500 \times g, 15$ minutes), then stored $\left(-20^{\circ} \mathrm{C}\right)$ for subsequent analysis of GSK2190915 (lower limit of qualification of $5 \mathrm{ng} / \mathrm{mL}$ ) by a validated method based on protein precipitation, followed by high-performance liquid chromatography tandem mass spectrometry analysis, as described previously. ${ }^{9}$

\section{Safety}

Adverse events (AEs), clinical laboratory tests, physical examination, vital signs, 12-lead electrocardiogram, and pulmonary function tests, were recorded throughout the study. The severity and causality of AEs were assessed before study was unblinded.

\section{Statistical analysis}

Study completion by at least 16 subjects provided at least $90 \%$ power to detect a $40 \%$ attenuation of the placebo response in the minimum $\mathrm{FEV}_{1}$ absolute change from baseline within the 2-hour period following allergen challenge on Day 3; using a two-sided 5\% significance level, assuming a within-subject standard deviation of $0.27 \mathrm{~L}$ and a mean placebo response of $-0.87 \mathrm{~L}$. The primary endpoint was the minimum FEV absolute change from baseline within the 2-hour period after allergen challenge on Day 3 of each treatment. The change from allergen challenge baseline $\mathrm{FEV}_{1}$ over time on Day 3 was analyzed using a repeated-measures model (including time point, period, treatment, treatment-by-time). The minimum $\mathrm{FEV}_{1}$ absolute change from baseline within the 2-hour period following allergen challenge on Day 3 was analyzed using a mixed-effects model (including period, treatment, and covariates for pre-dose $\mathrm{FEV}_{1}$ on Day 1). A similar analysis was performed for the weighted mean $\mathrm{FEV}_{1}$ within the 2-hour period after allergen challenge on Day 3. Pharmacokinetic and safety data were summarized and listed by treatment group.

\section{Results \\ Subject demographics}

Nineteen subjects ( 18 males and 1 female, mean age 35 years, mean $\mathrm{FEV}_{1} 3.80 \mathrm{~L}$, mean $\mathrm{FEV}_{1}$ predicted 92.8\%) were 
enrolled in the study (patient demographics and characteristics are shown in Table 1). The mean $\mathrm{FEV}_{1}$ percentage fall from baseline during the screening allergen challenge was $33.4 \%$ (range $20.8 \%$ to $56.5 \%$ ). Three subjects were withdrawn from the study due to AEs. All available data from subjects who received at least one dose of study medication were included in the analysis of efficacy, pharmacokinetics, and safety. There were no major protocol deviations.

\section{Efficacy}

Figure 2 shows the time profile of the EAR after treatment with GSK2190915 and placebo on Day 3 following allergen challenge; GSK2190915 $10 \mathrm{mg}$ and $50 \mathrm{mg}$ attenuated the placebo response in a dose-dependent manner.

The primary endpoint analysis of minimum $\mathrm{FEV}_{1}$ absolute change from baseline showed statistically significant attenuation of the fall in $\mathrm{FEV}_{1}$ for GSK2190915 $10 \mathrm{mg}$ and $50 \mathrm{mg}$ compared with placebo (Figure 3); the mean treatment differences were $0.21 \mathrm{~L}(95 \%$ confidence interval [CI] $0.04 \mathrm{~L}$, $0.38 \mathrm{~L})$ and $0.41 \mathrm{~L}(95 \% \mathrm{CI} 0.24 \mathrm{~L}, 0.58 \mathrm{~L})$, respectively, corresponding to a mean attenuation of $18.6 \%$ and $36.0 \%$ of the placebo response to allergen challenge, respectively. There was a significant difference between GSK2190915 $50 \mathrm{mg}$ and $10 \mathrm{mg}$ in the minimum $\mathrm{FEV}_{1}$ absolute change from baseline; the mean treatment difference was $0.20 \mathrm{~L}$ (95\% CI 0.03 L, 0.36 L).

Compared with placebo, GSK2190915 $50 \mathrm{mg}$, but not GSK2190915 $10 \mathrm{mg}$, significantly attenuated the weighted mean $\mathrm{FEV}_{1}$ absolute change from baseline (Figure 3 ).

Table I Patient demographics and characteristics (all subjects population)

\begin{tabular}{|c|c|}
\hline Number of subjects & Total $(n=19)$ \\
\hline Number of subjects planned, $n$ & 18 \\
\hline $\begin{array}{l}\text { Number of subjects randomized and administered } \\
\text { first dose, } n\end{array}$ & 19 \\
\hline Number of subjects completed as planned, n (\%) & $16(84)$ \\
\hline \multicolumn{2}{|l|}{ Number of subjects withdrawn, $\mathrm{n}(\%)$} \\
\hline $\mathrm{AE}$ & $3(16)$ \\
\hline Other reason & 0 \\
\hline \multicolumn{2}{|l|}{ Subject demographics and characteristics } \\
\hline Age (years), mean (SD) & $35.0(10.32)$ \\
\hline Male, n (\%) & $18(95)$ \\
\hline BMI $\left(\mathrm{kg} / \mathrm{m}^{2}\right)$, mean $(\mathrm{SD})$ & $25.24(3.78)$ \\
\hline \multicolumn{2}{|l|}{ Race, n (\%) } \\
\hline White & $16(84)$ \\
\hline Other & $3(16)$ \\
\hline $\mathrm{FEV}_{1}(\mathrm{~L})$, mean $(\mathrm{SD})$ & $3.8(0.75)$ \\
\hline \% predicted $\mathrm{FEV}$, mean $(\mathrm{SD})$ & $92.8(12.76)$ \\
\hline
\end{tabular}

Abbreviations: $A E$, adverse event; $B M I$, body mass index; $\mathrm{FEV}_{1}$, forced expiratory volume in I second; SD, standard deviation; $n$, number.
The mean treatment differences were $0.12 \mathrm{~L}(95 \%$ CI $-0.01 \mathrm{~L}, 0.24 \mathrm{~L})$ and $0.30 \mathrm{~L}(95 \% \mathrm{CI} 0.18 \mathrm{~L}, 0.43 \mathrm{~L})$ for GSK2190915 $10 \mathrm{mg}$ and $50 \mathrm{mg}$ compared with placebo, respectively, corresponding to mean attenuation of $21.5 \%$ and $56.2 \%$ of the placebo response, respectively.

\section{Pharmacokinetics}

On Day 3, at 2 hours after dosing with GSK2190915 $10 \mathrm{mg}$ and $50 \mathrm{mg}$, the mean $(95 \% \mathrm{CI})$ plasma concentrations were $83.4 \mathrm{ng} / \mathrm{mL}(62.3,104.5)$ and $418.9 \mathrm{ng} / \mathrm{mL}(311.0,526.7)$, respectively.

\section{Safety}

There were 19 mild-to-moderate AEs (Table 2), all of which resolved spontaneously. Eight were deemed at least possibly related to treatment; of those eight, four occurred on GSK2190915 $10 \mathrm{mg}$, one on GSK2190915 $50 \mathrm{mg}$, and three on placebo. The most frequent AE was headache. There were no serious AEs.

Three subjects were withdrawn from the study due to AEs. One subject had high fasting blood glucose before dosing on Day 1 of the first treatment period, which was not noted until after dosing and could not have been due to treatment. A second subject had a flu-like illness during the third treatment period (placebo), and was withdrawn as it was not considered safe to perform the allergen challenge. A third subject received GSK2190915 $50 \mathrm{mg}$ during the first treatment period and subsequently completed a 25-day washout period. Alanine aminotransferase (ALT) was increased in his pre-dose sample from the second treatment period. He received a single GSK2190915 $10 \mathrm{mg}$ dose before being withdrawn from the study; subsequent monitoring showed a decline in ALT. The raised ALT was deemed by the investigator to be possibly related to treatment.

\section{Discussion}

GSK2190915 caused dose-related inhibition of the EAR in subjects with mild asthma. We have shown that $50 \mathrm{mg}$ administered once-daily had a significantly greater effect than $10 \mathrm{mg}$ once-daily. This study shows the utility of the EAR for investigating the pharmacological dose-response effects of novel drugs in humans.

Compared with placebo, GSK2190915 50 mg once-daily for 3 days caused $36 \%$ and $56 \%$ mean attenuation of the minimum and weighted mean $\mathrm{FEV}_{1}$ change from baseline, respectively, in subjects with mild asthma; both changes were statistically significant. In our previously reported study, ${ }^{7}$ GSK2190915 $100 \mathrm{mg}$ once-daily caused 33\% and 63\% 


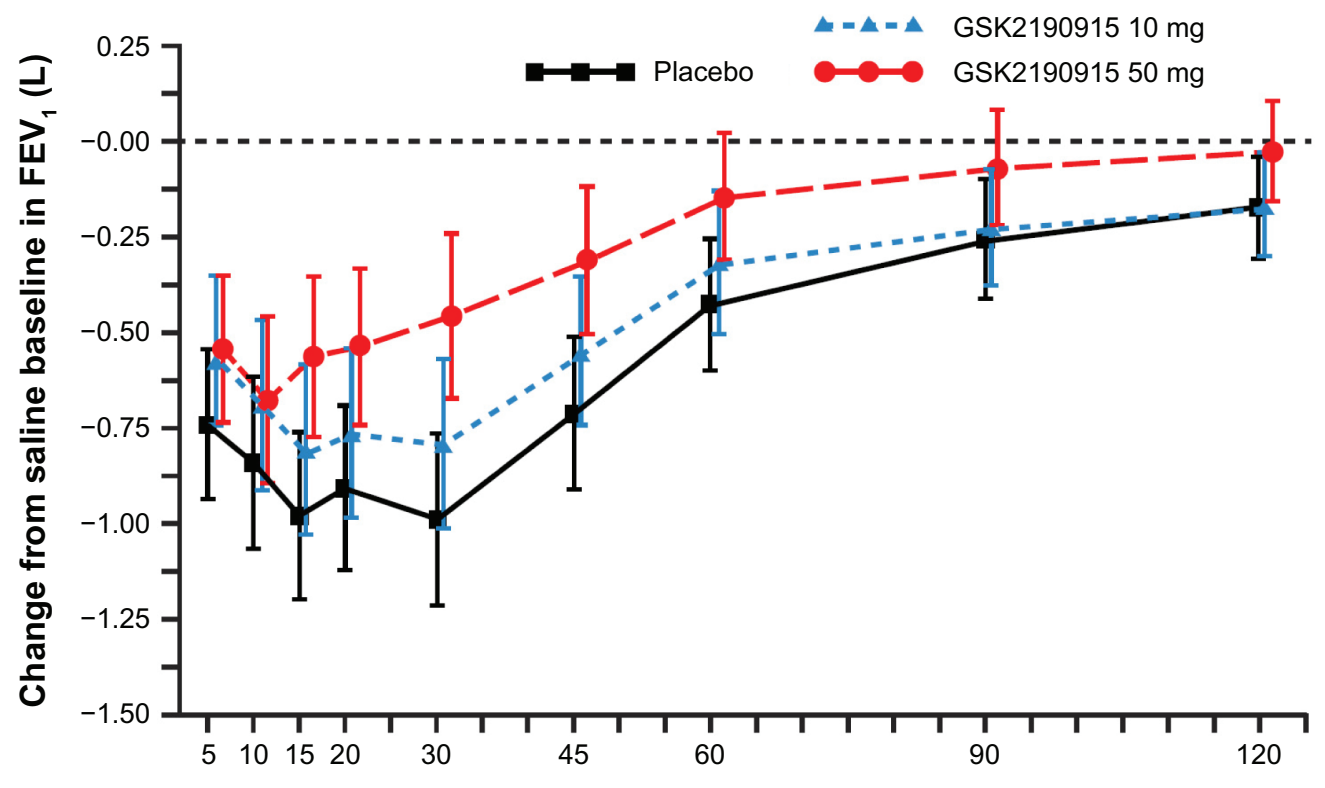

Time post-allergen challenge minutes

Figure 2 Adjusted mean $(95 \% \mathrm{Cl})$ absolute change in $\mathrm{FEV}$, versus time on Day 3 (efficacy population). Abbreviations: $\mathrm{Cl}$, confidence interval; $\mathrm{FEV}_{1}$, forced expiratory volume in I second.

mean attenuation of the minimum and weighted mean $\mathrm{FEV}_{1}$ change from baseline compared with placebo, respectively. Thus, 50 and $100 \mathrm{mg}$ had very similar effects, suggesting both of the doses were at the top of the dose response curve for EAR.

As the $50 \mathrm{mg}$ dose was shown to have a similar effect on EAR to that reported with a $100 \mathrm{mg}$ dose, ${ }^{7}$ it would be of interest to assess whether the lower doses of GSK2190915 used in this study also protect against LAR. Assessment of other efficacy outcomes, such as airway hyperresponsiveness to methacholine, and airway or blood markers of inflammation, would also have been useful. However, such assessments would have required a more complex study design; as the priority of the study was to measure the dose response effect on the EAR, additional assessments were not included. The effect of GSK2190915 $50 \mathrm{mg}$ and $100 \mathrm{mg}$ once-daily on the EAR

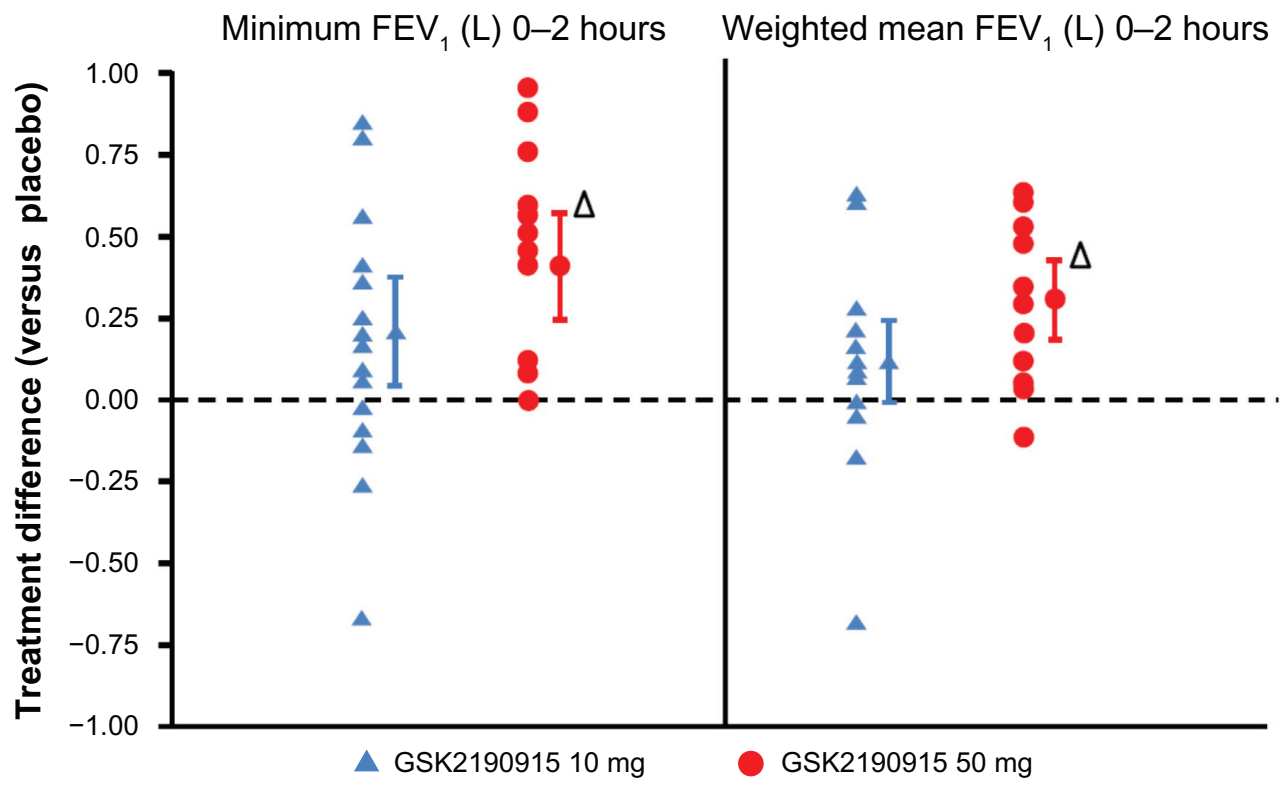

Figure 3 Adjusted mean treatment differences $(95 \% \mathrm{Cl}$ ) for allergen challenge: absolute change from saline baseline in minimum and weighted mean EAR on Day 3 (efficacy population).

Note: ${ }^{\triangle}$ Difference between $50 \mathrm{mg}$ and $10 \mathrm{mg}$ statistically significant $(P<0.05)$.

Abbreviations: $\mathrm{Cl}$, confidence interval; EAR, early asthmatic response; $\mathrm{FEV}_{1}$, forced expiratory volume in I second. 
Table 2 Adverse events (all subjects population)

\begin{tabular}{|c|c|c|c|}
\hline \multirow[t]{2}{*}{ Preferred term, n (\%) } & \multirow{2}{*}{$\begin{array}{l}\text { Placebo } \\
(n=\mid 7)\end{array}$} & \multicolumn{2}{|l|}{ GSK2 I 909 I 5} \\
\hline & & $10 \mathrm{mg}(\mathrm{n}=18)$ & $50 \mathrm{mg}(\mathrm{n}=19)$ \\
\hline Headache & $2(12)$ & $4(22)$ & 0 \\
\hline Dizziness & 0 & 0 & I (5) \\
\hline Oropharyngeal pain & 0 & I (6) & I (5) \\
\hline Cough & 0 & 0 & I (5) \\
\hline Influenza & I (6) & 0 & 0 \\
\hline Nasopharyngitis & 0 & I (6) & 0 \\
\hline Arthralgia & 0 & I (6) & 0 \\
\hline Myalgia & 0 & I (6) & 0 \\
\hline Dental caries & I (6) & 0 & 0 \\
\hline Nausea & I (6) & I (6) & 0 \\
\hline Chest pain & 0 & I (6) & 0 \\
\hline $\begin{array}{l}\text { Alanine aminotransferase } \\
\text { increased }\end{array}$ & 0 & 0 & I (5) \\
\hline
\end{tabular}

is similar to that previously reported for the clinical dose of the leukotriene antagonist montelukast. ${ }^{10,11}$ Furthermore, this effect is also similar to that observed in studies using FLAP inhibitors. ${ }^{12,13}$ These studies confirm the role of cysLTs in acute allergic bronchoconstriction; however, it would be useful to compare the magnitude of the effect of the GSK2190915 $50 \mathrm{mg}$ dose with other classes of drugs, although such studies have not been performed to date.

Compared with placebo, GSK2190915 $10 \mathrm{mg}$ once-daily for 3 days caused $18 \%$ and $21 \%$ mean attenuation of the minimum and weighted mean $\mathrm{FEV}_{1}$ change from baseline, respectively; only the minimum mean change was significantly different from placebo. Thus, $10 \mathrm{mg}$ appears to be a suboptimal therapeutic dose.

The effects of GSK2190915 $10 \mathrm{mg}$ and $50 \mathrm{mg}$ doses on the EAR correlate well with those of the same doses on urinary $\mathrm{LTE}_{4}$ suppression in healthy subjects; ${ }^{9} 10 \mathrm{mg}$ suppressed $\mathrm{LTE}_{4}$ by $40 \%$, and $50 \mathrm{mg}$ suppressed $\mathrm{LTE}_{4}$ almost completely. We did not include urine $\mathrm{LTE}_{4}$ in this study; however, the plasma concentrations were similar to those in healthy volunteers. ${ }^{9}$ The data suggest that the use of urine $\mathrm{LTE}_{4}$ measurements to assess the effects of drugs on leukotriene production could be a good predictor of the likely effects on allergic bronchoconstriction.

In our previously reported study on asthma, the geometric mean peak concentration $\left(\mathrm{C}_{\max }\right)$ for $100 \mathrm{mg}$ of GSK2190915 was 671 (95\% CI: 494, 910) ng/mL, ${ }^{7}$ compared with the observed $\mathrm{C}_{\max }$ values for $10 \mathrm{mg}$ (83.4 [95\% CI: 62.3, 104.5] ng/mL) and $50 \mathrm{mg}(418.9$ [95\% CI: 311.0, 526.7] $\mathrm{ng} / \mathrm{mL}$ ) doses in this study. These dose-related increases in GSK2190915 pharmacokinetics in patients with asthma have also been observed in healthy subjects using GSK2190915 doses up to $1,000 \mathrm{mg}$.
Ideally, we could have studied more doses of GSK2190915 in the current study, but there is a limit to the number of allergen challenges that subjects with asthma are willing to tolerate. We therefore chose not to include a dose of $100 \mathrm{mg}$, but to use results from our previously reported study $^{7}$ for comparison. Although the two studies used different subjects, they all had mild asthma, the procedure for allergen challenge was identical, the clinical sites were the same, the two studies were conducted at the same time, and the inclusion criteria were the same, except that subjects in our previously reported study were also required to have a LAR. Therefore, comparison of the two sets of results seems reasonable. In retrospect, a dose between $10 \mathrm{mg}$ and $50 \mathrm{mg}$ would have yielded useful information about the therapeutic dose. Nevertheless, the EAR data from our previous ${ }^{7}$ and current studies provide a guide for doses that can be included in larger and longer dose-ranging studies on clinical endpoints such as lung function and asthma control.

While allergen challenge studies of more than one dose have been conducted with other drugs such as inhaled corticosteroids, these studies have included both the EAR and LAR. We are unaware of any other studies that have used the EAR alone to study the dose-response effects of novel drugs. We have demonstrated that the EAR is a model that can be used in relatively small numbers of subjects to define the dose-response effects. This approach is faster and more efficient than alternatives such as longer studies of $\mathrm{FEV}_{1}$.

In general, GSK2190915 was well-tolerated in this short study. Of the three subjects who were withdrawn from the study because of AEs, two had abnormal blood results in pre-dose blood samples and the other was withdrawn during placebo treatment. Studies with longer duration of dosing and larger numbers of subjects are required to define the potential adverse effects of GSK2190915.

\section{Conclusion}

In conclusion, GSK2190915 caused dose-dependent attenuation of the EAR response to inhaled allergen. GSK2190915 $50 \mathrm{mg}$ attenuated the EAR similarly to GSK2 $190915100 \mathrm{mg}$ in our previous study, ${ }^{7}$ suggesting that $50 \mathrm{mg}$ is at the top of the dose-response curve. This study shows how the EAR can be used to assess the therapeutic dose of a new treatment for allergic asthma.

\section{Acknowledgments}

The authors thank the staff and subjects at the three investigative sites: Hammersmith Medicines Research, Medicines Evaluation Unit, and Respiratory Clinical Trials. The authors 
also acknowledge Dr Chang-Qing Zhu and Dr Parminder Saggu for statistical and programming support, and Dr Claire Ambery for pharmacokinetic analysis and pharmacodynamic analyses. GlaxoSmithKline funded this study. Editorial assistance in the form of formatting the final draft manuscript for submission was provided by Sue Casson of FWG Scientific Communications.

\section{Disclosure}

This study was funded by GlaxoSmithKline. Sandra E Kent was paid by GlaxoSmithKline for the submitted work; Dave Singh has received lecture fees, research grants, consultancy fees, and support for conference attendance from various pharmaceutical companies including AstraZeneca, Almirall, Boehringer Ingleheim, Chiesi, Cipla, Forest, GlaxoSmithKline, Merck, Novartis, Nycomed, and Roche in the previous 3 years; and Virginia Norris and Jane H Bentley are employed by, and hold shares in, GlaxoSmithKline. Malcolm Boyce has no conflicts of interest to declare. The authors report no other conflicts of interest in this work.

\section{References}

1. Montuschi P, Peters-Golden ML. Leukotriene modifiers for asthma treatment. Clin Exp Allergy. 2010;40(12):1732-1741.

2. Peters-Golden M, Henderson WR. Leukotrienes. $N$ Engl J Med. 2007;357(18):1841-1854.

3. Grant GE, Rokach J, Powell WS. 5-Oxo-ETE and the OXE receptor. Prostaglandins Other Lipid Mediat. 2009;89(3-4):98-104.

4. Gaber F, Daham K, Higashi A, et al. Increased levels of cysteinylleukotrienes in saliva, induced sputum, urine and blood from patients with aspirin-intolerant asthma. Thorax. 2008;63(12):1076-1082.

5. Pavord ID, Ward R, Woltmann G, Wardlaw AJ, Sheller JR, Dworski R. Induced sputum eicosanoid concentrations in asthma. Am J Respir Crit Care Med. 1999;160(6):1905-1909.
6. Evans JF, Ferguson AD, Mosley RT, Hutchinson JH. What's all the FLAP about?: 5-lipoxygenase-activating protein inhibitors for inflammatory diseases. Trends Pharmacol Sci. 2007;29(2):72-78.

7. Kent SE, Boyce M, Diamant Z, et al. The 5-lipoxygenase activating protein inhibitor, GSK2190915, attenuates the early and late responses to inhaled allergen in mild asthma. Clin Exp Allergy. 2013;43(2): 177-186.

8. Lorrain DS, Bain G, Correa LD, et al. Pharmacology of AM803, a novel selective five-lipoxygenase-activating protein (FLAP) inhibitor in rodent models of acute inflammation. Eur J Pharmacol. 2010;640(1-3):211-218.

9. Bain G, King CD, Schaab K, et al. Pharmacodynamics, pharmacokinetics and safety of GSK2190915, a novel oral anti-inflammatory 5-lipoxygenase-activating protein inhibitor. $\mathrm{Br} \mathrm{J}$ Clin Pharmacol. 2013;75(3):779-790.

10. Singh D, Richards D, Knowles RG, et al. Selective inducible nitric oxide synthase inhibition has no effect on allergen challenge in asthma. Am J Respir Crit Care Med. 2007;176(10):988-993.

11. Diamant Z, Grootendorst DC, Veselic-Charvat M, et al. The effect of montelukast (MK-0476), a cysteinyl leukotriene receptor antagonist, on allergen-induced airway responses and sputum cell counts in asthma. Clin Exp Allergy. 1999;29(1):42-51.

12. Hamilton AL, Watson RM, Wyile G, O'Byrne PM. Attenuation of early and late phase allergen-induced bronchoconstriction in asthmatic subjects by a 5-lipoxygenase activating protein antagonist, BAYx 1005 . Thorax. 1997;52(4):348-354.

13. Diamant Z, Timmers MC, van der Veen H, et al. The effect of MK-0591, a novel 5-lipoxygenase activating protein inhibitor, on leukotriene biosynthesis and allergen-induced airway responses in asthmatic subjects in vivo. J Allergy Clin Immunol. 1995;95(1 Pt 1):42-51.

14. Hui KP, Taylor IK, Taylor GW, et al. Effect of a 5-lipoxygenase inhibitor on leukotriene generation and airway responses after allergen challenge in asthmatic patients. Thorax. 1991;46(3):184-189.

15. Nasser SM, Bell GS, Foster S, et al. Effect of the 5-lipoxygenase inhibitor ZD2138 on aspirin-induced asthma. Thorax. 1994;49(8):749-756.

16. Busse WW, Brazinsky S, Jacobson K, et al. Efficacy response of inhaled beclomethasone dipropionate in asthma is proportional to dose and is improved by formulation with a new propellant. JAllergy Clin Immunol. 1999;104(6):1215-1222.

17. Bleecker ER, Bateman ED, Busse WW, et al. Once-daily fluticasone furoate is efficacious in patients with symptomatic asthma on low-dose inhaled corticosteroids. Ann Allergy Asthma Immunol. 2012;109(5): 353-358. e4.
International Journal of General Medicine

\section{Publish your work in this journal}

The International Journal of General Medicine is an international peer-reviewed open-access journal that focuses on general and internal medicine, pathogenesis, epidemiology, diagnosis, monitoring and treatment protocols. The journal is characterized by the rapid reporting of reviews, original research and clinical studies across all disease areas.

\section{Dovepress}

A key focus is the elucidation of disease processes and management protocols resulting in improved outcomes for the patient.The manuscript management system is completely online and includes a very quick and fair peer-review system. Visit http://www.dovepress.com/ testimonials.php to read real quotes from published authors. 